I was right to be nervous; this is a tough read. Professor Brakel seeks to present psychoanalysis as a theory of mind, using arguments from the general philosophy of mind. Specifically, she seeks to argue that there are two types of thinking described in psychoanalytic theory: what one might think of as 'everyday' secondary process thinking and primary process thinking that is found in dreams, 'slips of the tongue' and other 'a-rational' forms of thought. What Brakel wants to emphasise is that unconscious mentation is not irrational but a-rational, by which she means that it operates, as it were, on a different epistemological footing.

I need to be honest here; I did not understand the book fully. Not that Brakel is not a readable writer; she has a warm and engaging style, which is welcome in such an intellectually challenging work. She is clearly an expert in her field, and her enthusiasm for her subject comes clearly across. Yet I could not help feeling stymied, brought up short against a level of discourse that was inaccessible to me. In the context of the argument, I was surprised not to see some discussion of Matte Bianco's work on different forms of mentation but then I realised that I would probably not understand where his work fits in. The book also requires the reader to engage with basic psychoanalytic tenets $a$ priori, which to my mind gave a hint of something tautological.

I suspect that this is a book by a philosopher of psychoanalysis, written for other philosophers of psychoanalysis; and I am in awe at the level of discussion there must be at their dinner parties. But my mind is not shaped for such 'sportive tricks' (as it were), so I came away feeling frustrated. Perhaps Professor Brakel could write an introductory text that would let non-analysts join the discussion.

Gwen Adshead Consultant Psychiatrist, Dadd Centre, Broadmoor Hospital, Crowthorne, Berkshire RG45 7EG, UK. Email: gwen.adshead@wlmht.nhs.uk

doi: 10.1192/bjp.bp.110.078329

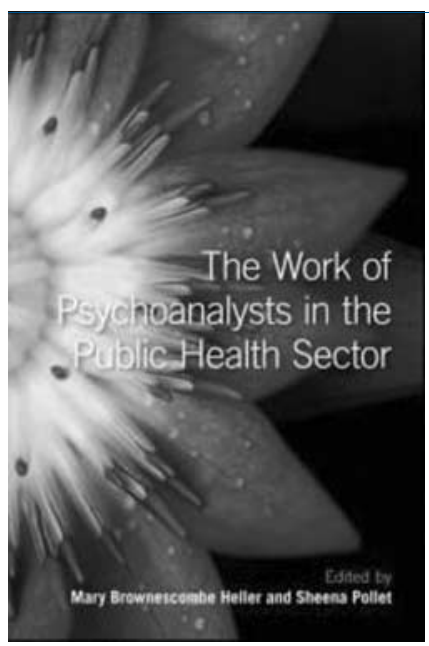

\section{The Work of}

Psychoanalysts in the Public Health Sector

Edited by

Mary Brownsecombe Heller

\& Sheena Pollet.

Routledge. 2009.

£22.99 (pb). 232 pp.

ISBN: 9780415484299
In the manner of great music compilation albums, the authors of this volume have managed to squeeze in virtually 'all killer and (almost) no filler'. The book opens with a brief overture that gives the reader a chance to hear the themes that will be developed throughout - that analytic thinking adds depth and complexity to general psychiatric practice more generally and remains relevant even within the confines of a market-based health economy. The latter perhaps leading to the aptly named title of the first chapter, 'Making a little go a long way'.

The choice of chapters and the order in which they are set gives the book a clear structure, taking the reader from working with people in the early phases of their development through to adulthood. The book then moves beyond individuals into how analytic ideas can be extended to have value and meaning within mental health work more generally, including the poignant chapter on helping 'doctors in trouble' wherein clinical material from analytic sessions with two different struggling doctors is given. Analytic theory can be atonal on the page but the descriptions of clinical work that illuminate this book provide a richness that keeps one hooked. They also serve to show how working in the National Health Service is a matter of engaging in applied rather than pure psychoanalysis.

The leitmotif in the work appeared to be the idea of containment, which was elegantly explained, albeit in a number of chapters. As somebody embedded within an analytic training, this duplication of content was one of the minor drawbacks of the book but to those coming afresh, repetition of these ideas may be the mother of study. The few other disharmonious moments were as a result of what might be regarded as a slightly self-satisfied view of psychoanalysis, although these were tempered by a willingness on the part of most authors to engage with the rest of psychiatry instead of feeling embattled by that contact. With this in mind, in the chapter 'Psychoanalysis and general psychiatry' by the late Richard Lucas, there is a quote from Freud that would best be kept in mind by practitioners who are on either side of, or indeed straddle, this imaginary divide: 'What is opposed to psychoanalysis is not psychiatry but psychiatrists'.

Jon Patrick Forensic Psychotherapy Specialist Registrar, NHS Lothian,

Psychotherapy Department, Royal Edinburgh Hospital, Tipperlinn Road, Edinburgh EH10 5HF, UK. Email: jon.patrick@nhslothian.scot.nhs.uk

doi: 10.1192/bjp.bp.109.075549

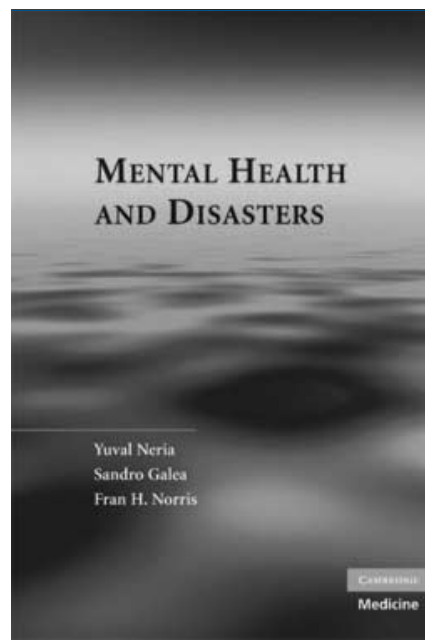

\section{Mental Health and Disasters}

Edited by Yuval Neria,

Sandro Galea \& Fran H. Norris. Cambridge University Press. 2009 f80 (hb). 640pp. ISBN: 9780521883870

Bold are the publishers and authors who assert that any text is 'the definitive' one, as has been stated here, but most certainly this book does represent a very comprehensive coverage of the relationship between mental health and disaster. By 'disasters' the authors mean so-called natural incidents, technological incidents and those events associated with mass violence.

The book is divided into seven thematic sections, incorporating 35 chapters. A wide range of key topics are addressed, including specialist mental health interventions, vulnerable groups, traumatic grief, resilience and psychopathology in all its guises. In addition, there is valuable coverage of cross-cultural issues, physical health problems, and journalism and the media. 